\title{
Cranioplastia: parietal versus prótese customizada
}

\author{
Cranioplasty: parietal versus customized prosthesis
}

Tatiana Hara $^{1}$
Clarice Abreu dos Santos
Albuquerque de Farias ${ }^{1}$
Mayra Joan Marins da
Costa $^{1}$
Ricardo Jose Lopes da
CruZ $^{2}$

Trabalho realizado no Centro de Cirurgia Crânio-maxilofacial do Instituto Nacional de

Traumatologia e Ortopedia (INTO), Rio de Janeiro, RJ, Brasil. Trabalho apresentado no $47^{\circ}$ Congresso Brasileiro de Cirurgia Plástica, Vitória, ES, 2010, Ganhador do Prêmio Ivo Pitanguy.

Artigo submetido pelo SGP (Sistema de Gestão de Publicações) da RBCP.

Artigo recebido: $21 / 10 / 2010$ Artigo aceito: 5/2/2011

\begin{abstract}
RESUMO
Introdução: Os defeitos ósseos da calota craniana ocorrem frequentemente pela perda tecidual relacionada ao trauma ou para tratamento de tumores, sendo a maior causa de deformidade do crânio pós-trauma a craniectomia realizada na intervenção neurocirúrgica para tratamento da injúria cranioencefálica. As principais indicações para a correção dos defeitos cranianos incluem proteção do tecido cerebral, correção estética e melhora clínica, que envolve a pulsação de tecidos moles e a sensação de insegurança relatada pelo paciente. Defeitos extensos da calvária de espessura total são de grande desafio ao cirurgião pelo seu curso complexo, que envolve cirurgias prévias, infecções locais e osteonecrose, que leva à dificuldade na escolha do melhor método reconstrutivo. Método: Análise retrospectiva dos casos operados entre Janeiro de 2008 e Abril de 2010 para reconstrução da calota craniana realizados no Centro de Cirurgia Crânio-maxilofacial - Instituto Nacional de Traumatologia e Ortopedia (MS). Resultados: Foram analisados 11 pacientes com defeitos extensos de espessura total da calota craniana operados no período, destes 9 foram submetidos a correção com enxerto ósseo autólogo de tábua externa do parietal e 2 com prótese customizada. Conclusão: O protocolo do nosso centro define que a primeira opção de reconstrução para defeitos extensos da calota craniana de espessura total é o enxerto autólogo de tábua externa do osso parietal sem craniectomia. Nos casos selecionados em que esse método reconstrutivo não pode ser utilizado, a opção é pelo uso de prótese customizada.
\end{abstract}

Descritores: Crânio. Traumatismos Craniocerebrais. Osso Parietal. Próteses e Implantes. Cirurgia Plástica.

\begin{abstract}
Background: Cranial bone deformities are most often the result of trauma or extirpation for tumors, and the principal cause of the cranial deformities after cranial trauma is related to the craniectomy realized in neurosurgical approach for the treatment of brain damage. The reconstructive goals in cranioplasty are to provide protection of the brain, restore preinjury appearance and to lead clinical improvement like soft tissue pulsation and the unsafe feeling. Large full thickness skull defects can be quite challenging for the surgeon because of its complexity course which includes previous surgery, local infection and osteonecrosis. These factors lead to the difficult choice of the best reconstructive material. Methods: A prospective study of the patients treated, from January 2008 to April 2010, for the calvaria reconstruction at Centro de Cirurgia Crânio-maxilofacial - Instituto Nacional de Traumatologia e Ortopedia (MS). Results: Eleven patients with large full thickness skull defects submitted to cranioplasty were analysed. Nine of them were treated with parietal outer table without craniectomy and two were treated with customized prosthesis. Conclusions: In large full thickness skull defects the first method of reconstruction is the parietal outer table without craniectomy. In selected cases, when this reconstructive method can not be used, the option for the cranioplasty is the customized prosthesis.

Keywords: Skull. Craniocerebral Trauma. Parietal Bone. Prosthesis and Implants. Plastic Surgery.
\end{abstract}

1. Membro da Sociedade Brasileira de Cirurgia Plástica (SBCP); Estagiária do Centro de Cirurgia Crânio-maxilofacial do Instituto Nacional de Traumatologia e Ortopedia - MS, Rio de Janeiro, RJ, Brasil.

2. Membro Titular da SBCP; Coordenador do Centro de Cirurgia Crânio-maxilofacial do Instituto Nacional de Traumatologia e Ortopedia - MS, Rio de Janeiro, RJ, Brasil. 


\section{INTRODUÇÃO}

O traumatismo cranioencefálico decorrente de acidentes automobilísticos, quedas e agressões interpessoais leva muitas vezes à necessidade de uma abordagem neurocirúrgica para o tratamento de injúrias cranioencefálicas, durante a fase aguda do tratamento. E este é o fator etiológico mais comum dos defeitos cranianos adquiridos ${ }^{1}$.

A cranioplastia para a correção de extensos defeitos cranianos é especialmente desafiadora para o cirurgião. Comumente estes pacientes apresentam um curso clínico complexo, que envolve múltiplas operações prévias, além da dificuldade técnica que depende de material e equipe adequados para execução².

Nas perdas ósseas da calota craniana de espessura total, a cranioplastia tem o principal objetivo de proteger o encéfalo e corrigir uma deformidade estética extremamente aparente. Além disso, quando os defeitos são grandes o suficiente para permitir que o escalpo exerça pressão direta sobre o cérebro, é observada melhoria na fala e nos quadros de hemiparesia após a reconstrução craniana $^{3}$ (Figura 1).

A cranioplastia para o tratamento de perdas de espessura total da calvária inclui diversos métodos de reconstrução. Dentre os materiais autólogos utilizados com esse objetivo destacam-se os enxertos autólogos da tábua externa do osso parietal, costelas e crista ilíaca. A escolha da área doadora de enxerto depende de diversos fatores, que incluem a semelhança com o tecido a ser reparado na área do defeito, a facilidade na coleta do enxerto, a proximidade com a área a ser reconstruída e a capacidade de osteointegração.

Com a evolução dos biomateriais, os materiais aloplásticos vêm sendo utilizados com maior amplitude nas diversas

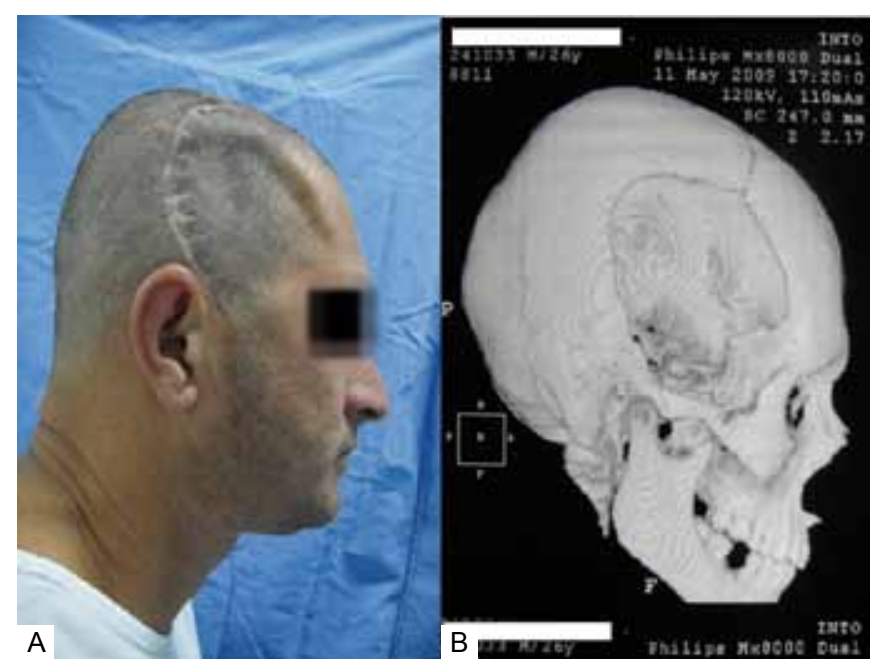

Figura 1 - Defeito craniano frontotemporal. A: Defeito frontotemporal. B: Tomografia computadorizada com reconstrução tridimensional. áreas da medicina. Diversos são os materiais utilizados com essa finalidade, dentre eles o polietileno poroso, a biocerâmica e a malha de titânio. A confecção de próteses customizadas, que possuem dimensões e formas adequadas para a correção de cada tipo de defeito, permite o uso cada vez mais abrangente do material aloplástico. $\mathrm{O}$ recurso da prototipagem rápida em saúde consiste na confecção de um modelo tridimensional compatível com a estrutura anatômica a ser tratada, obtido por meio de informações coletadas a partir de dados do exame de imagem (tomografia computadorizada). É através destes protótipos, que retratam de forma fidedigna o defeito, que as próteses customizadas são confeccionadas, tornando todo o processo de tratamento mais eficiente, simples e preciso ${ }^{4}$.

\section{MÉTODO}

Realizada análise retrospectiva dos pacientes operados para reconstrução de calota craniana, entre janeiro de 2008 a abril de 2010, realizados no Centro de Cirurgia Crâniomaxilofacial do Instituto Nacional de Traumatologia e Ortopedia (MS).

Os critérios de inclusão foram: os defeitos residuais de espessura total decorrentes de abordagem neurocirúrgica para o tratamento de traumatismos cranioencefálico, acidente vascular cerebral e tumores. Os critérios de exclusão foram: defeitos da calota craniana de espessura parcial, tumores ósseos e malformações congênitas.

As informações foram coletadas por meio do levantamento de dados obtidos em prontuário e avaliação das tomografias computadorizadas realizadas no pré-operatório.

\section{RESULTADOS}

Um total de 11 pacientes operados no período foram incluídos no estudo e analisados.

Os defeitos cranianos de espessura total analisados foram decorrentes de sequelas para abordagem neurocirúrgica prévia, tendo como etiologia prevalente o traumatismo craniano por acidente com motocicleta com 9 casos, um caso de agressão interpessoal e um de ressecção de tumor (meningioma).

As regiões parietal e frontal foram as mais acometidas, sendo a região parietal isoladamente comprometida em 2 pacientes, região frontal isoladamente em 6 e região frontotemporal em 2.

As áreas dos defeitos variaram de $1,5 \mathrm{a} 182 \mathrm{~cm}^{2}$. O defeito de maior dimensão foi o que comprometeu o crânio bilateralmente (região frontoparietal esquerda e parietal direita), com área total de $182 \mathrm{~cm}^{2}$ (Tabela 1).

Em 9 casos, o método de reconstrução escolhido foi a utilização do enxerto ósseo de tábua externa do parietal. 


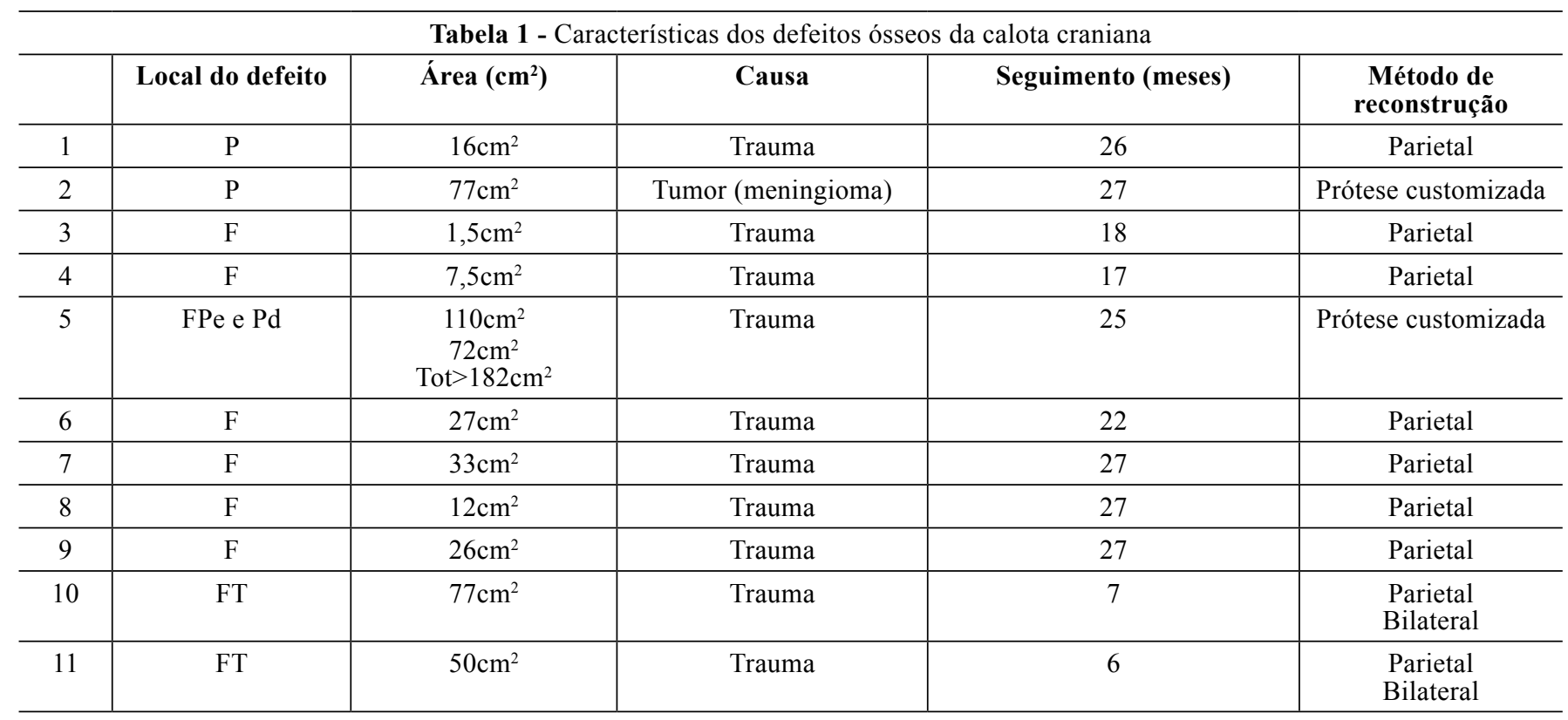

$* \mathrm{P}=$ Parietal, $\mathrm{F}=$ Frontal, $\mathrm{FP}=$ Frontoparietal, $\mathrm{FT}=$ Frontotemporal, e $=$ esquerdo, $\mathrm{d}=$ direito.

Nesses casos, as dimensões dos defeitos foram inferiores a 77 $\mathrm{cm}^{2}$. Na técnica utilizada nesse tipo de reconstrução, optouse pela incisão coronal, com abordagem inicial à área do defeito craniano e, posteriormente, à área doadora do enxerto ósseo na região parietal, onde a coleta foi feita por meio de remoção da tábua externa do osso parietal sem craniectomia. A correção do defeito foi feita com a fixação do enxerto com material de fixação interna rígida. Ao final da cirurgia foi realizada a rotação de um retalho de pericrânio recobrindo a área reconstruída. Em dois desses casos que possuíam as maiores dimensões entre os defeitos reconstruídos com enxerto autólogo de parietal $\left(50\right.$ e $\left.77 \mathrm{~cm}^{2}\right)$, uma tática cirúrgica aplicada para a correção foi a retirada da tábua externa do parietal bilateralmente (Figuras 2 e 3 ).

Em 2 casos, a opção foi pelo uso de próteses customizadas para a correção do defeito craniano, sendo o material aloplástico utilizado a biocerâmica. Nesses casos, os defeitos reconstruídos foram maiores que $77 \mathrm{~cm}^{2}$. O acesso cirúrgico para a colocação deste material foi através de uma incisão coronal, permitindo a abordagem da área do defeito e posterior colocação e fixação da prótese customizada (Figura 4).

O tempo de acompanhamento no pós-operatório variou de 7 a 27 meses, e em nenhum dos casos operados foram evidenciadas infecções pós-operatórias ou extrusão do material de reconstrução.

Em um caso, a cranioplastia foi realizada após um quadro de infecção local com prótese de polietileno poroso encaminhado ao serviço. O material aloplástico foi retirado e substituído por enxerto autólogo de parietal, com melhora do quadro infeccioso.

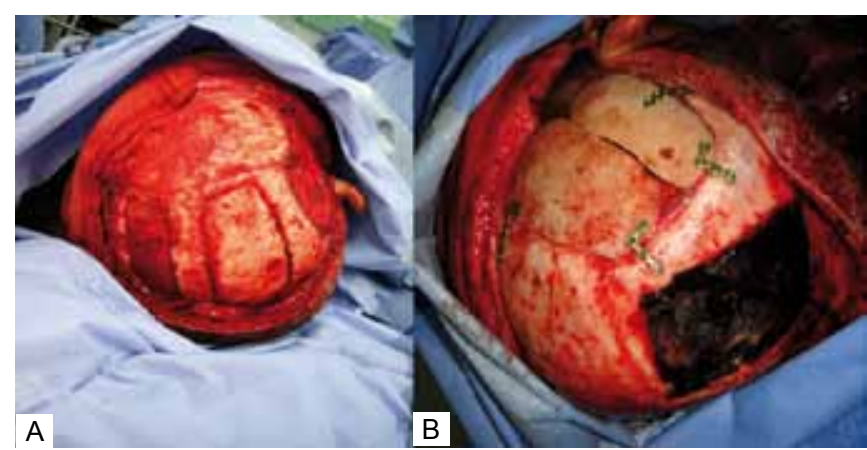

Figura 2 - Enxerto de parietal para correção de defeito extenso frontotemporal. A: Parietal doador de enxerto ósseo bilateral. B: Enxerto ósseo reparando área de defeito.

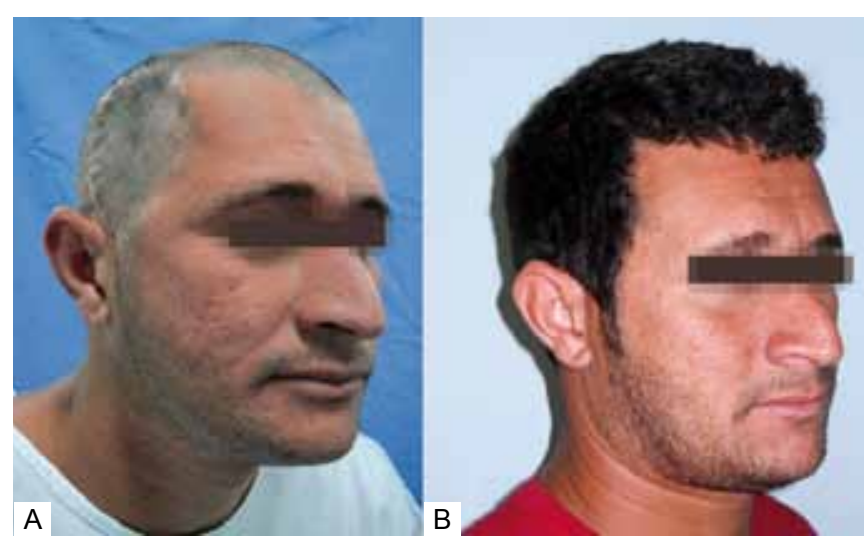

Figura 3 - Cranioplastia com enxerto de tábua externa de parietal. A: Pré-operatório. B: Pós-operatório de 6 meses. 


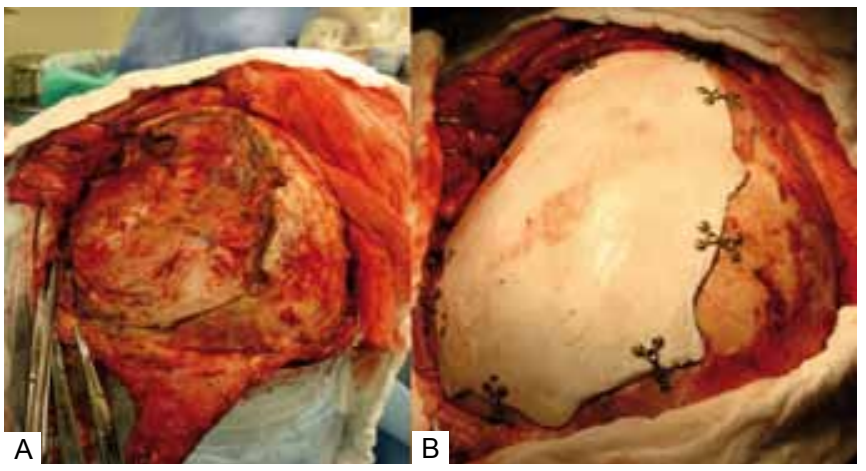

Figura 4 - Cranioplastia com prótese customizada. A: Área do defeito. B: Defeito reconstruido.

\section{DISCUSSÃO}

Os defeitos de espessura total da calota craniana de pequenas dimensões são corrigidos preferencialmente com a utilização do enxerto ósseo de tábua externa do parietal. A indicação deste tipo de reconstrução é adequada, já que as dimensões da área doadora são suficientes para correção do defeito, o uso do enxerto autólogo carrega consigo os diversos benefícios discutidos adiante e as complicações do método são minimizadas pela área limitada a ser coletada na área doadora.

Nos defeitos extensos da calota craniana, a preferência deve ser, sempre que possível, pela utilização do enxerto ósseo da tábua externa do parietal ${ }^{2}$. Nos casos tratados em nosso centro, quando avaliadas isoladamente as dimensões do defeito na escolha do método a ser utilizado, defeitos de até $77 \mathrm{~cm}^{2}$ foram corrigidos adequadamente com a utilização do enxerto de parietal. Nesses casos, as dimensões da área doadora podem ser ampliadas com a retirada do enxerto ósseo de parietal bilateralmente.

O enxerto ósseo doado da calota craniana é preferido quando comparado às demais áreas doadoras, como crista ilíaca e costelas. Seus principais benefícios são: a proximidade com a área a ser corrigida, sendo acessado através de uma incisão única, gerando uma cicatriz estética no couro cabeludo, possuir as mesmas características e mesma origem embriológica do osso na área de perda e apresentar volume e contorno satisfatórios. $\mathrm{Na}$ área doadora é mantida a cortical interna com espessura e rigidez necessárias para a proteção cerebral neste sítio, além disso, é mantido um contorno visualmente aceitável ${ }^{1}$.

A boa nutrição garante a manutenção deste enxerto e minimiza o risco de infecção e extrusão. Alguns fatores corroboram para isso, como o fato deste enxerto ser de origem membranosa, a técnica cirúrgica preconizar o bom contato ósseo, garantido por uma fixação adequada, e a utilização rotineira do retalho de pericrânio cobrindo o enxerto e aumentando o aporte nutricional. Devido a essas características, nos casos de infecção com uso de aloplásticos, uma opção ideal é a retirada do material de reconstrução e sua substituição por enxerto ósseo ${ }^{1}$.

Em um dos casos em que foi utilizada a prótese customizada, as dimensões do defeito eram muito extensas, impossibilitando que o enxerto de parietal bilateral fosse suficiente para cobrir toda a área de perda óssea de $182 \mathrm{~cm}^{2}$. Não utilizamos associações de materiais autólogos e aloplásticos em um mesmo paciente, pela possibilidade da somatória de complicações que cada método já possui isoladamente.

No segundo caso em que se optou pela reconstrução com o uso de prótese customizada, o defeito possuía dimensões limítrofes para ser reconstruído com o enxerto de parietal (77 $\mathrm{cm}^{2}$ ), mas o defeito comprometia a região parietal. Esse fato limitou a possibilidade de expansão da área doadora com a utilização da tábua externa do parietal bilateralmente.

Nos casos avaliados, o sítio mais frequentemente acometido foi a região frontal (73\%), compatível com dados da literatura, que apontam este sítio como o mais atingido $(53,2 \%)$. A região parietal isoladamente foi o segundo local mais acometido da calvária (18\%), em contraposição aos estudos que a colocam em terceiro lugar em incidência, preterida pela região temporal ${ }^{5}$.

A avaliação da perda óssea da calvária é importante não somente para a mensuração da área do defeito, mas também para avaliar a localização da perda óssea, já que o comprometimento do parietal torna inviável a sua utilização como área doadora. Esse fato ocorreu em ambos os casos em que a opção de reconstrução foi o uso da prótese customizada.

A utilização do enxerto autólogo de tábua externa do parietal traz benefícios indiscutíveis ao paciente, mas para que estes fatores positivos sejam aproveitados é necessário que a indicação do uso do enxerto ósseo de parietal seja correta e precisa.

Em todos os casos é essencial uma avaliação adequada da história do paciente e de seu exame físico, para que o melhor método reconstrutivo seja indicado.

Pacientes adultos do gênero masculino possuem um crânio com uma espessura média de $0,7 \mathrm{~cm}$, dimensões suficientes para realizar a bipartição da cortical externa do osso parietal, doadora do enxerto ósseo. Os pacientes pediátricos, idosos e do gênero feminino, anatomicamente, possuem uma espessura do osso parietal mais estreita, o que os torna, na maioria das vezes, incompatíveis para a doação de enxerto ósseo proposto.

A avaliação das comorbidades do paciente durante a anamnese é de grande importância, já que o risco cirúrgico é aumentado com a coleta do enxerto ósseo de parietal. Existe um aumento da perda sanguínea decorrente da abordagem da díploe, com rica vascularização, com a retirada da cortical externa doadora do osso craniano. A injúria cranioencefálica 
é mais incidente pela espessura da calota craniana, o que requer uma abordagem muito cuidadosa. O tempo operatório é prolongado quando comparado à colocação isolada da prótese customizada, já que se soma o tempo da coleta do enxerto.

Nesses casos avaliados, em que a utilização do enxerto de calota craniana não é viável, a melhor opção reconstrutiva é o uso da prótese customizada.

Após avaliação inicial e indicação de prótese customizada, é necessário realizar a tomografia computadorizada e consequente prototipagem, para que o defeito seja idealmente analisado. Através deste protótipo realiza-se a customização da prótese que corrigirá inteiramente o defeito.

A prototipagem rápida na área de saúde soma diversos benefícios, além da customização de próteses. No préoperatório, permite ao cirurgião realizar a simulação prévia da cirurgia e avaliar locais de incisões e fixação da prótese, comparar a simetria da reconstrução com o lado sadio, além de permitir a detecção de possíveis dificuldades técnicas, reduzindo o tempo cirúrgico. Além disso, uma comunicação mais clara pode ser estabelecida com o paciente com explicações mais efetivas do procedimento a ser realizado, garantindo maior satisfação no pós-operatório ${ }^{6}$.

Os materiais aloplásticos mais utilizados para customização incluem a biocerâmica, a malha de titânio e o metilmetacrilato, não havendo consenso na literatura atual quanto ao material mais apropriado para uso neste tipo de reconstrução em relação à extrusão do material e infecções. Quando comparados ao enxerto ósseo, apresentam a vantagem de não serem reabsorvidos, porém as chances de infecção e perda do implante são mais significativas ${ }^{2,6-8}$.

\section{CONCLUSÃO}

O protocolo de tratamento do Centro de Cirurgia Crâniomaxilofacial do INTO (MS) preconiza que, nos defeitos de espessura total da calota craniana em que a área de perda é pequena, o método reconstrutivo de eleição seja a utilização do enxerto ósseo de tábua externa do parietal.
Nos defeitos de espessura total da calota craniana de grandes dimensões, é essencial a avaliação cuidadosa de cada paciente, com anamnese e exame físico adequados, além de análise detalhada da tomografia computadorizada, buscando o melhor método de correção.

Mesmo nos grandes defeitos da calvária priorizamos a utilização do enxerto ósseo de tábua externa de parietal sem craniectomia. Com o objetivo de empregar todos os benefícios do método, quando o defeito craniano é muito extenso, ampliamos a área doadora com o uso do parietal doador bilateralmente.

Em alguns casos, existem fatores limitantes ao emprego do enxerto, como dimensões inapropriadas ao seu uso, comprometimento do osso parietal, espessura inadequada do parietal ou comorbidades associadas. Nestes casos selecionados, a opção é pelo uso da prótese customizada.

\section{REFERÊNCIAS}

1. Sahoo N, Roy ID, Desai AP, Gupta V. Comparative evaluation of autogenous calvarial bone graft and alloplastic materials for secondary reconstruction of cranial defects. J Craniofac Surg. 2010;21(1):79-82.

2. Zins JE, Moreira-Gonzalez A, Papay FA. Use of calcium-based bone cements in the repair of large, full-thickness cranial defects: a caution. Plast Reconstr Surg. 2007;120(5):1332-42.

3. Yaremchuck MJ. Acquired cranial bone deformities. In: Mathes SJ, Hentz VR, eds. Plastic surgery. $2^{\text {nd }}$ ed. Philadelphia:Elsevier;2006. p.547-62.

4. Chim H, Schantz JT. New frontiers in calvarial reconstruction: integrating computer-assisted design and tissue engineering in cranioplasty. Plast Reconstr Surg. 2005;116(6):1726-41.

5. Moreira-Gonzalez A, Jackson IT, Miyawaki T, Barakat K, DiNick V. Clinical outcome in cranioplasty: critical review in long-term followup. J Craniofac Surg. 2003;14(2):144-53.

6. Cao D, Yu Z, Chai G, Liu J, Mu X. Application of EH compound artificial bone material combined with computerized three-dimensional reconstruction in craniomaxillofacial surgery. J Craniofac Surg. 2010;21(2):440-3.

7. Abuzayed B, Tuzgen S, Canbaz B, Yuksel O, Tutunculer B, Sanus GZ. Reconstruction of growing skull fracture with in situ galeal graft duraplasty and porous polyethylene sheet. J Craniofac Surg. 2009;20(4):1245-9.

8. Chao MT, Jiang S, Smith D, DeCesare GE, Cooper GM, Pollack IF, et al. Demineralized bone matrix and resorbable mesh bilaminate cranioplasty: a novel method for reconstruction of large-scale defects in the pediatric calvaria. Plast Reconstr Surg. 2009;123(3):976-82. 